Original Article

\title{
EFFECT OF AMLODIPINE ON ENTEROPATHY INDUCED BY INDOMETHACIN IN RATS
}

\author{
YARA ANNOUF ${ }^{*}$, SHAZA AL-LAHAM ${ }^{1}$, EYAD AL-SHATTI ${ }^{2}$ \\ 1Pharmacology and Toxicology Department, Faculty of Pharmacy, Damascus University, Damascus, Syria, ${ }^{2}$ Pathology Department, Faculty \\ of Medicine, Damascus University, Damascus, Syria \\ Email: yara.anouf93@gmail.com
}

Received: 25 Jan 2020, Revised and Accepted: 23 Mar 2020

\begin{abstract}
Objective: Non-steroidal anti-inflammatory drugs (NSAIDs) have become well known for causing gastroduodenal mucosal damage. In addition, they are also known to affect the small intestine in humans. Amlodipine is a third-generation dihydropyridine-type calcium channel blocker; it can inhibit inflammatory cytokines and enhance antioxidant defenses. The aim of this study was to evaluate the effect of Amlodipine on indomethacininduced enteropathy in rats.
\end{abstract}

Methods: Enteropathy was induced by subcutaneous indomethacin (Indo) prepared in $5 \%$ sodium bicarbonate administrated at a dose rate of 9 $\mathrm{mg} / \mathrm{kg}$ for two days at $24 \mathrm{~h}$ intervals. Amlodipine $(10 \mathrm{mg} / \mathrm{Kg}$ body weight po) was administrated for seven consecutive days beginning $24 \mathrm{~h}$ after the first Indo injection. Rats were sacrificed under ether anesthesia on the $8^{\text {th }}$ day. The small intestinal injury was assessed by body weight loss, small intestine weight/length ratio, macroscopic damage, histological study, as well as by biochemical measurement of reduced glutathione (GSH), lipid peroxides and superoxide dismutase (SOD) activity in the small intestine tissue.

Results: The results showed that Amlodipine didn't decrease body weight loss, it decreased small intestine weight/length ratio, macroscopic and microscopic small intestinal damage scores caused by administration of Indo. It also increased SOD activity and decreased lipid peroxidation. The effect on the level of GSH wasn't observed. No statistical significance was observed when previous findings were compared to Indo induced enteropathy group $(\mathrm{p}>0.05)$.

Conclusion: Amlodipine didn't produce an obvious enhancement in enteropathy induced by Indo in rats.

Keywords: NSAIDS, Enteropathy, Amlodipine, Histopathology study, Superoxide dismutase activity, Reduced glutathione, Lipid peroxides

(C) 2020 The Authors. Published by Innovare Academic Sciences Pvt Ltd. This is an open access article under the CC BY license (http://creativecommons.org/licenses/by/4.0/) DOI: http://dx.doi.org/10.22159/ijcpr.2020v12i3.38229. Journal homepage: https://innovareacademics.in/journals/index.php/ijcpr

\section{INTRODUCTION}

Non-steroidal anti-inflammatory drugs (NSAIDs) are some of the most commonly prescribed drugs in the world. As a result of their anti-inflammatory, analgesic, and antiplatelet effects [1].

Nonsteroidal anti-inflammatory drugs (NSAIDs) have become well known for causing gastroduodenal mucosal damage. In addition, they are also known to affect the small intestine in humans [2]. NSAID-induced enteropathy has gained much attention due to the introduction of new emerging diagnostic modalities, capsule endoscopy (CE) and device-assisted enteroscopy as well as due to the increased use of aspirin and NSAIDs. Previous attention or studies have focused primarily on upper GI events but recent researches have shifted to the small bowel and colon during chronic NSAID use [3]. NSAIDs can cause a variety of functional and structural abnormalities in the small intestine, such as increased intestinal permeability, intestinal inflammation, protein loss, blood loss, ulceration, perforation, diaphragm-like strictures, and ileal dysfunction [4]. Several factors are involved in the pathogenesis of NSAID-induced enteropathy, including a deficiency in prostaglandins (PGs), bile acid, bacterial flora, and nitric oxide (NO) [5].

NSAIDs have recently increased; therefore, increased awareness of the gastrointestinal side effects is needed. However, effective prevention and treatment of the side effects of NSAIDs in the small intestine have not yet been determined [6].

In spite of relatively intense research, there is still no effective, safe and tolerable drug treatment available in the market for the management of NSAID-enteropathy [7].

Amlodipine is a third-generation dihydropyridine-type calcium channel blocker commonly used for the treatment of hypertension [8]. Experimental studies have shown that Amlodipine can inhibit inflammatory cytokines and enhance antioxidant defenses [9].
However, the effect of Amlodipine on NSAIDs induced enteropathy has not yet been studied.

\section{MATERIALS AND METHODS}

\section{Animals}

Female and male wistar albino rats weighing 160-280 g were purchased from the Scientific Research Center, Damascus, Syria. The animals were provided with ad libitum feed and water. The animals were kept at controlled environmental conditions (temperature $23 \pm 2$ ${ }^{\circ} \mathrm{C}$, humidity $55 \pm 15 \%$, lighting regimen of $12 \mathrm{~h}$ light: 12 -h dark). They were acclimatized for one week before any experiment.

\section{Experimental design}

Rats were divided into three groups:

Group I: normal control group (6 rats in this group) received oral vehicle (physiological saline).

Group II: Indo control group (7 rats in this group) received subcutaneous Indo prepared in $5 \%$ sodium bicarbonate, administered at a dose rate of $9 \mathrm{mg} / \mathrm{kg}$ for two days at $24 \mathrm{~h}$ intervals. It also received an oral vehicle (physiological saline).

Group III: Amlodipine treated group (6 rats in this group) received Amlodipine dissolved in physiological saline $(10 \mathrm{mg} / \mathrm{kg}$ body weight po) for seven consecutive days beginning $24 \mathrm{~h}$ after the first Indo injection, Indo $(9 \mathrm{mg} / \mathrm{kg} /$ day) was given at a dose rate of $9 \mathrm{mg} / \mathrm{kg}$ for two days at $24 \mathrm{~h}$ intervals in order to induce enteropathy.

\section{Tissue collection and preparation}

On day eight, each subgroup of animals across all groups was sacrificed. The small intestine was removed and opened longitudinally along their antimesenteric borders, tissues were washed in saline solution, and any macroscopic change was checked. 
A precise evaluation of the lesions was made after each specimen was fixed in $10 \%$ formalin.

Intestinal tissue from jejunum was collected and stored at- $80{ }^{\circ} \mathrm{C}$ till further analysis.

\section{Clinical findings}

During the study, rats were checked daily for body weight, behavioural changes, food intake, intestinal bleeding and stool consistency. The bodyweight of animals was measured at regular time intervals from day 0 to 7 . Change of body weight (\%) was calculated.

\section{Small intestine weight/length ratio}

The length and weight of the small intestine were measured for the estimation of:

Weight of the intestine $(\mathrm{g}) /$ length of the intestine $(\mathrm{cm})$ ratio

\section{Macroscopic characters [10]}

Table 1: Macroscopic inflammation assessment of the small intestine

\begin{tabular}{ll}
\hline Score & Macroscopic score \\
\hline 0 & No visible change \\
1 & Hyperemia at sites \\
2 & Lesions having diameter $1 \mathrm{~mm}$ or less \\
3 & Lesions having diameter $2 \mathrm{~mm}$ or less $($ number $<5)$ \\
4 & Lesions having diameter $2 \mathrm{~mm}$ or less $($ number $5-10)$ \\
5 & Lesions having diameter $2 \mathrm{~mm}$ or less $($ number $>10)$ \\
6 & Lesions having diameter more than $2 \mathrm{~mm}($ number $<5)$ \\
7 & Lesions having diameter more than $2 \mathrm{~mm}($ number $5-10)$ \\
8 & Lesions having diameter more than $2 \mathrm{~mm}($ number $>10)$ \\
\hline
\end{tabular}

\section{Histopathological observations}

A portion of the distal small intestine (jejunum) specimen from each rat was fixed with $10 \%$ formalin, embedded in paraffin wax and cut into sections of $5 \mathrm{~mm}$ thickness. The sections were stained with hematoxylin and eosin ( $\mathrm{H}$ and $\mathrm{E})$ dye for histopathological observations. The following histological features were examined by an unbiased pathologist (AM) blinded to the experimental design: grade and type of inflammation, an extension of inflammation throughout the gastrointestinal wall (mucosa, submucosa, muscular layer and serous membrane), presence of Lymphocytic aggregate/Follicle, Necrosis, Granuloma, Cryptitis, Crypt abscess and epithelial lesions (erosions, ulcers) [11].

\section{Biochemical estimations}

Accurately weighed tissues from jejunum were homogenized in cold phosphate-buffered saline $[\mathrm{pH} 7.4,50 \mathrm{mmol}]$ to prepare $10 \%$ homogenate and the suspension was divided into three portions. One part of tissue suspension was mixed with $0.2 \mathrm{ml} 5 \%$ trichloroacetic acid (TCA) for measurement of GSH levels; the second part of tissue suspension was used for measurement SOD activity. One and two parts of tissue homogenate were centrifuged at $10000 \mathrm{~g}$ for $20 \mathrm{~min}$ at 4 ${ }^{\circ} \mathrm{C}$ and supernatant was used for assay GSH levels and SOD activity.

The remaining of the third portion of tissue homogenate was used for the estimation of Lipid peroxides levels.

\section{Assay of reduced glutathione (GSH)}

Reduced glutathione (GSH) was measured by reaction with $5,5^{\prime}-$ dithiobis (2-nitrobenzoic acid) (DTNB) to give a compound that absorbs at $412 \mathrm{~nm}$ (Ellman's method). In short, each sample cuvette contained $2 \mathrm{ml} 0.6 \mathrm{mmol}$ DTNB in $0.2 \mathrm{M}$ sodium phosphate, $\mathrm{pH}$ 8.0, 0.1-0.2 ml supernatant fraction, and $0.2 \mathrm{M}$ phosphate buffer to a final volume of $3 \mathrm{ml}$. (Measurement of the $\mathrm{pH}$ in the cuvette showed that the buffer capacity was sufficient to neutralize the trichloroacetic acid present in the sample, and an assay of known amounts of GSH in the presence of 0.1-0.2 $\mathrm{ml}$ 5\% trichloroacetic acid demonstrated that this substance did not interfere with the procedure in any other way.) The reference cuvette contained $0.1-0.2 \mathrm{ml} 5 \%$ trichloroacetic acid instead of sample, and the reaction was started by the addition of supernatant to the sample cuvette [12]. It is expressed as $\mu \mathrm{M}$ of GSH per gram of tissue.

\section{Assay of superoxide dismutase (SOD) activity}

The recommended procedure is as follows. First, a certain amount of pyrogallol solution $\left(60 \mathrm{mmol}\right.$ in $\left.1 \mathrm{mmol} \mathrm{HCl}, 37^{\circ} \mathrm{C}\right)$ was thoroughly mixed with pH 7.4 Tris- $\mathrm{HCl}$ buffer $\left(0.05 \mathrm{M}, 37^{\circ} \mathrm{C}\right)$ containing $1 \mathrm{mmol}$ Na2EDTA (to remove metal ions, which may catalyze the reaction); the total volume was adjusted to $3000 \mu \mathrm{l}$ using the buffer. The A325 $\mathrm{nm}$ value of the mixture without a sample was measured every $30 \mathrm{~s}$ for $5 \mathrm{~min}$ at $37^{\circ} \mathrm{C}$. Second, an amount of pyrogallol solution equal to that used in the first step was added to a mixture with a sample, and the total volume was adjusted to $3000 \mu \mathrm{l}$ using the buffer.

Enzyme activity, which corresponds to the amount of enzyme that inhibits auto-oxidation of pyrogallol by $50 \%$ was calculated and expressed per mg of protein [13].

\section{Assay of lipid peroxidation (TBARS)}

Lipid peroxidation, an indicator of mucosal injury induced by reactive oxygen species was measured as thiobarbituric acid reactive substance. Briefly, $0.5 \mathrm{ml}$ of small intestinal tissue homogenates prepared were reacted with $2 \mathrm{ml}$ of TBA reagent containing $0.375 \%$ TBA, $15 \%$ trichloroacetic acid and $0.25 \mathrm{~N} \mathrm{HCl}$. Samples were boiled for $15 \mathrm{~min}$, cooled and centrifuged. Absorbance of the supernatants was measured by spectrophotometer measured at $532 \mathrm{~nm}$. The concentration of MDA was calculated by the absorbance coefficient of MDA-TBA complex $\left(1.56 \times 10^{5} \mathrm{M} / \mathrm{cm}\right)$ and expressed in $\mu \mathrm{mol} / 100 \mathrm{~g}$ of tissue $[14,15]$.

\section{Statistical analysis}

Data analyses were achieved using a software program Graph Pad Prism version 8. Data were expressed as mean \pm SEM, and different groups were compared using one-way analysis of variance (ANOVA) followed by Sidak test for multiple comparisons for parametric data, and Kruskal-Wallis test followed by Dunn test for multiple comparisons for non-parametric data and parametric data that have shown non-normal distribution. $\mathrm{P}$ values less than 0.05 were considered significance statistically.

\section{RESULTS}

\section{Clinical findings, general observation and body weight change}

After $24 \mathrm{~h}$ of administration first dose of Indo, animals developed soft feces, weakness, decreased food intake and progressively body weight loss. All these symptoms reached a maximum at three days from first dose of Indo, and then these symptoms started to decrease gradually.

Compared with that of the normal control group, which revealed an increase in body weight $(1.63 \%)$, the bodyweight of the Indo control group at the end of the experiment was reduced by $(-4.58 \%)$ with statistical significance comparing with normal control group $(\mathrm{p}=0.0402)$.

Amlodipine treated group revealed a decrease in body weight ($8.49 \%$ ) with no statistical significance comparing with the Indo control group ( $\mathrm{p}=0.1891)$ (table 2). 
Table 2: Effect of amlodipine on the body weight in Indo induced enteropathy in rats

\begin{tabular}{llll}
\hline Parameter group & Initial body weight & Final body weight & Body weight change \% \\
\hline Normal control & $194.2 \pm 8.29$ & $196.8 \pm 7.78$ \\
Indo control & $204.1 \pm 13.14$ & $194.9 \pm 14.03$ & $1.63 \pm 2.76$ \\
Amlodipine treated & $216.7 \pm 9.09$ & $197.7 \pm 6.03$ & $-4.58 \pm 2.28^{*}$ \\
\hline
\end{tabular}

Values are given as mean \pm SEM values are statistically significant at ${ }^{*} \mathrm{P}<0.05$ between Normal and Indo control groups

\section{Small intestine weight/length ratio}

Small intestine weight/length ratio is a reliable indirect marker of the small intestinal inflammation. It was observed an increase in this ratio in the Indo control group; there was statistical significance comparing with normal control group $(\mathrm{p}=0.0372)$.

Amlodipine treated group revealed decrease in small intestine weight/length ratio with no statistical significance comparing with Indo control group ( $\mathrm{p}=0.1521$ ) (fig. 1).

\section{Macroscopic score}

The most sections of distal small intestine in normal control group didn't reveal any morphological changes. In contrast, subcutaneous injection of Indo produced damage in the distal small intestine. Adhesions, erosion, edema, hemorrhagic spots were noticed. These lesions have a diameter greater than $2 \mathrm{~mm}$, thus the morphological score in the Indo control group was significantly increased $(p=0.0006)$ as compared to normal control group.
Amlodipine treated group revealed reduce in the severity of the gross lesion (fig. 2) (table 3), but there was no statistical significance comparing with Indo control group $(\mathrm{p}=0.4172)$ (fig. 3$)$.

\section{Histopathological study}

The distal small intestine specimen of $50 \%$ of rats in the normal control group revealed an intact architecture, while the distal small intestine specimen of $50 \%$ of rats from this group revealed increased inflammatory cells infiltration, the inflammation was mild to moderate.

On the other hand the distal small intestine specimen of Indo control group revealed increased inflammatory cell infiltration, transmural inflammation, lymphocytic aggregate, cryptitis and ulcerations. There was statistical significance comparing with normal control group $(\mathrm{p}=0.0084)$.

Administration of Amlodipine as therapy revealed in some rats reduce in the severity of the injury of the distal small intestine (table 4) (fig. 4) with no statistical significance comparing with Indo control group $(p=0.3382)$ (fig. 5).

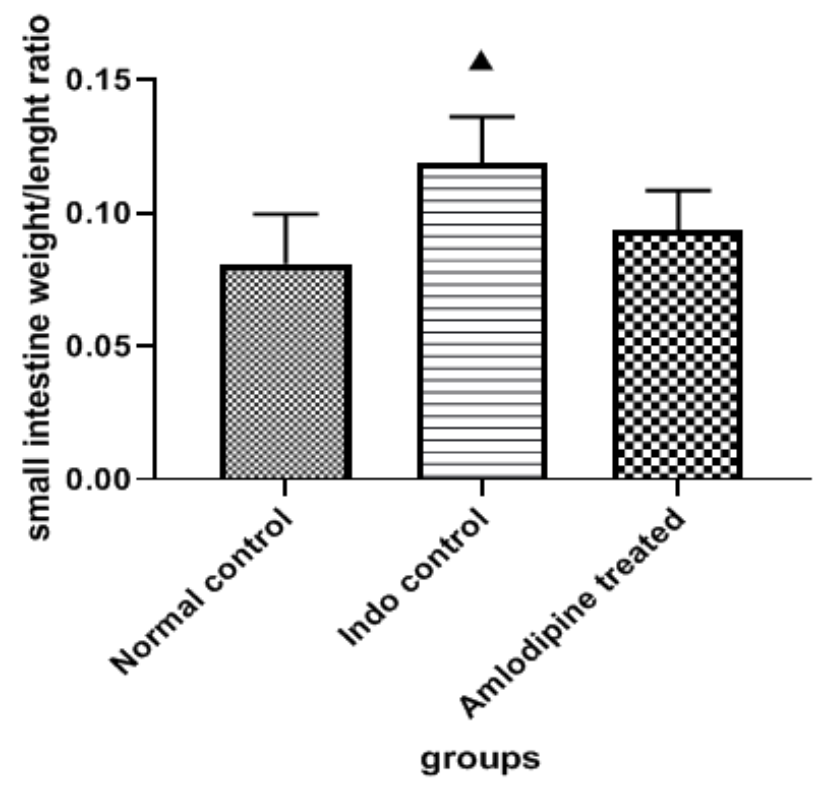

Fig. 1: Effect of amlodipine on small intestine weight/length ratio in Indo induced enteropathy in rats. Data are expressed as mean \pm SEM $\triangle$ Significant difference as compared to normal control group at $\mathrm{p}<0.05$

Table 3: Macroscopic score of different experimental groups

\begin{tabular}{|c|c|c|c|}
\hline Group macroscopic score & Normal control & Indo control & Amlodipine treated \\
\hline 0 & $5(83.33 \%)$ & & \\
\hline 1 & $1(16.67 \%)$ & & $1(16.67 \%)$ \\
\hline 2 & & & \\
\hline 3 & & & \\
\hline 4 & & & \\
\hline 5 & & & \\
\hline 6 & & $6(85.71 \%)$ & $5(83.33 \%)$ \\
\hline 7 & & $7(14.029 \%)$ & \\
\hline 8 & & & \\
\hline
\end{tabular}




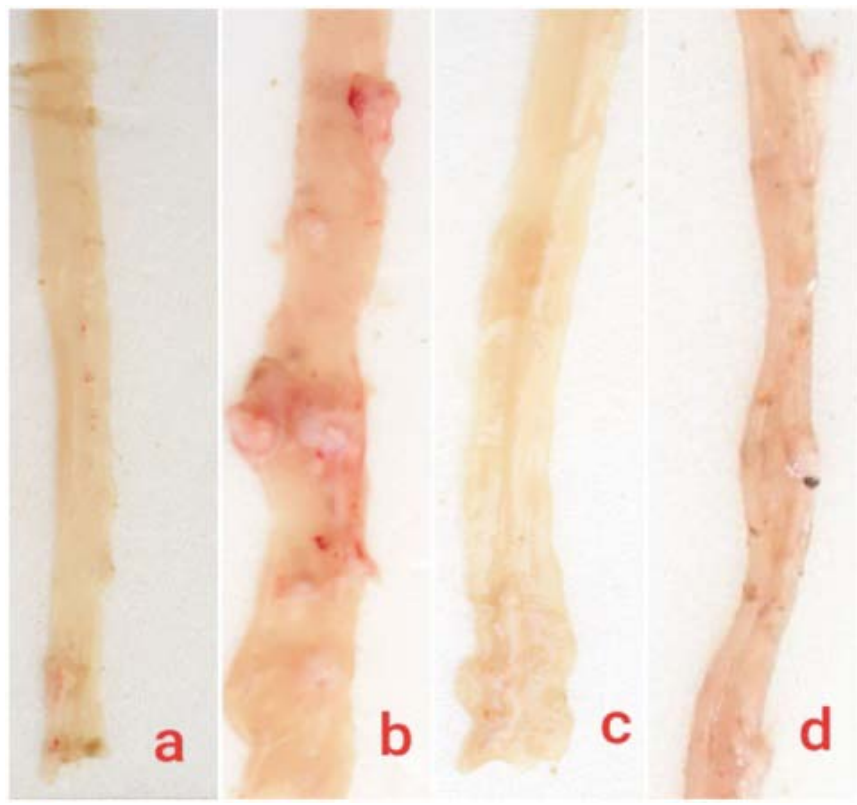

Fig. 2: Macroscopic appearances of the distal small intestine in Indo induced enteropathy in rats. a-Normal control group (score 0), bIndo control group (score 7), c-Amlodipine treated group (score 1), d-Amlodipine treated group (score 6)

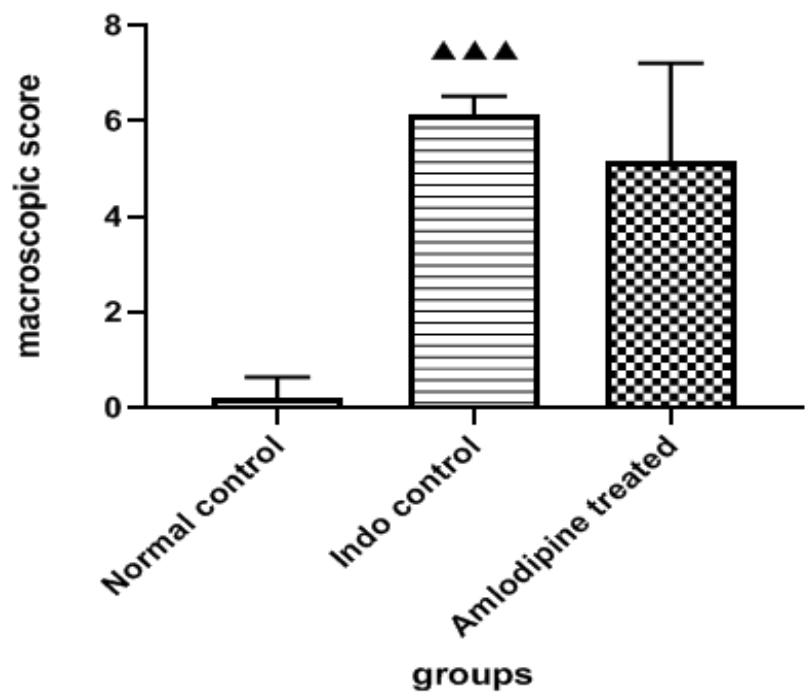

Fig. 3: Effect of Amlodipine on the macroscopic score in Indo induced enteropathy in rats. Data are expressed as mean \pm SEM $\triangle$ Significant difference as compared to the normal control group at $\mathbf{p}<0.001$

Table 4: Microscopic score of different experimental groups

\begin{tabular}{llll}
\hline Group microscopic score & Normal control & Indo control & Amlodipine treated \\
\hline 0 & $3(50 \%)$ & & $2(33.33 \%)$ \\
1 & $1(16.67 \%)$ & $2(28.57 \%)$ & $1(16.67 \%)$ \\
2 & $2(33.33 \%)$ & $2(28.57 \%)$ & $2(33.33 \%)$ \\
3 & & $3(16.67 \%)$ \\
4 & & & \\
5 & & & \\
7 & & & \\
8 & & & \\
9 & & & \\
10 & & & \\
\hline
\end{tabular}



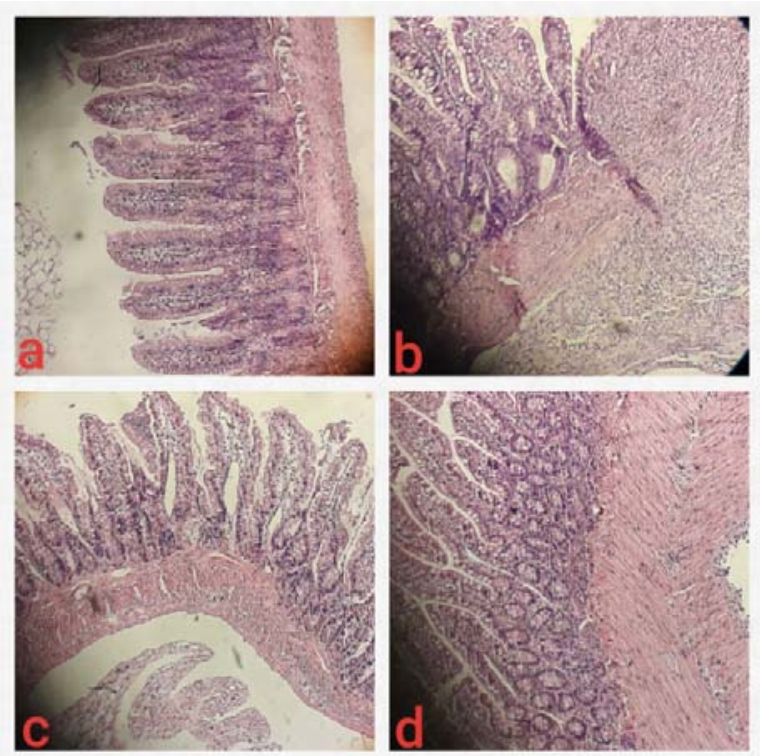

Fig. 4: Histological appearance of jejunum tissue sections, original magnification $\times 10$, a-Normal control group (grade 0 ) shows an intact architecture, b-Indo control group (grade 5) shows focal cryptitis, transmural inflammation and ulceration, c-Amlodipine treated group (grade 0) shows an intact architecture, d-Amlodipine treated group (grade 4) shows transmural inflammation and lymphocytic aggregate

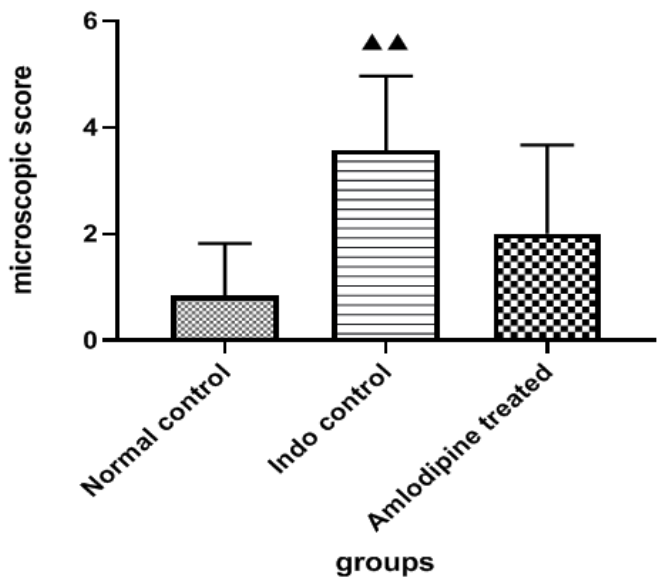

Fig. 5: Effect of Amlodipine on the microscopic score in Indo induced enteropathy in rats. Data are expressed as mean \pm SEM, $\triangle M S i g n i f i c a n t$ difference as compared to the normal control group at $p<0.01$

Table 5: Effect of Amlodipine on lipid peroxides, GSH and SOD activity in Indo induced enteropathy in rats

\begin{tabular}{llll}
\hline Group parameter & SOD activity & GSH levels $(\boldsymbol{\mu m} / \mathbf{g}$ of tissue) & Lipid peroxides $(\boldsymbol{\mu m o l} / \mathbf{1 0 0}$ g of tissue) \\
\hline Normal control & $0.588333 \pm 0.058675$ & $1.925 \pm 0.213239$ & $44.33333 \pm 4.333333$ \\
Indo control & $0.175714 \pm 0.05719^{*}$ & $1.391429 \pm 0.137207^{*}$ & $79.71429 \pm 16.53238^{*}$ \\
Amlodipine treated & $0.319333 \pm 0.190946$ & $1.133333 \pm 0.162714$ & $72.16667 \pm 12.53107$ \\
\hline
\end{tabular}

Amlodipine treated

Data are expressed as mean $\pm \mathrm{SEM}, *$ Significant difference as compared to normal control group at $\mathrm{p}<0.05$

\section{Biochemical assays}

Indo induced oxidative stress in the small intestine; it was evaluated by lipid peroxidation, SOD activity and GSH levels.

Indo increased the levels of lipid peroxides, decreased SOD activity and GSH levels in the distal small intestine; there was statistical significance comparing with the normal control group (SOD: $p=0.0413$, GSH: $p=0.0223$, Lipid peroxides: $p=0.0294$ )

Amlodipine treated group revealed a decrease in the levels of lipid peroxides, an increase in SOD activity. The levels of GSH in the distal small intestine tissues were decreased. There was no statistical significance comparing with the Indo control group (SOD: $\mathrm{p}=0.6746$, GSH: $\mathrm{p}=0.5996$, Lipid peroxides: $\mathrm{p}=0.6308$ ) (table 5).

\section{DISCUSSION}

The ability of nonsteroidal anti-inflammatory drugs (NSAIDs) to damage the gastric mucosa and exacerbate preexisting ulcers in the stomach and duodenum is well established. Over the past decade, there has been increasing recognition of the damaging effects of NSAIDs on more distal regions of the small intestine [16].

Indo is a potent non-steroidal anti-inflammatory drug of proven effectiveness in man and in animals. Similar to other anti- 
inflammatory agents, Indo has been reported to produce gastrointestinal irritation and ulceration in man as well as in animals [17]. Indo induces small intestinal and colonic ulceration in a dosedependent fashion in rodents [18]. Depending on the dose and route of Indo administration, as well as the strain of rat, Indo-induced jejunoileitis and intestinal inflammation usually resolves spontaneously and completely within 1-2 w [19]. YAMADA et al. have shown that one injection of Indo $(7.5 \mathrm{mg} / \mathrm{kg})$ produced acute injury and inflammation in the distal jejunum and proximal ileum that were maximal at three days and completely resolved within one week. Two daily subcutaneous injections of Indo produced a more extensive and chronic inflammation that lasted in an active form in more than $75 \%$ of the rats for at least two weeks [20]. This study has shown that the administration of two daily subcutaneous injections of Indo $(9 \mathrm{mg} / \mathrm{kg})$ was suitable to induce the injury in the small intestine.

Small bowel injury induced by NSAIDs is usually developed via COXdependent decreases in prostaglandin production and there is a very close association between NSAID-induced apoptosis and oxidative stress. Thus, NSAIDs have been shown to significantly increase intracellular ROS production [21]. The administration of Indo results in the generation of free radicals in enterocytes, possibly as a result of mitochondrial dysfunction produced and the infiltration of neutrophils into the mucosa [22].

In this study, Indo-induced enteropathy, as evidenced by body weight loss, reduction in food intake, increase in small intestine weight/length ratio, changes in biochemical parameters which include depletion of GSH, increased lipid peroxides levels and decreased SOD activity in small intestinal tissues. The macroscopic results revealed adhesions, erosion, edema, and hemorrhagic spots, as well as the microscopic score revealed increased inflammatory cells infiltration, transmural inflammation, lymphocytic aggregate, cryptitis and ulcerations.

The present study highlights the therapeutic effects of Amlodipine a third-generation dihydropyridine-type calcium channel blocker on Indo induced enteropathy in rats.

The effect of Amlodipine on bodyweight improvement wasn't observed. It decreased small intestine weight/length ratio with no statistical significance comparing with Indo control group. Administration of Amlodipine attenuated microscopic and macroscopic score with no statistical significance comparing with Indo control group. That was against the paper of Morsy et al. which showed that Amlodipine has an attenuating effect in ulcerative colitis in rats [9]. Also Kim et al. who demonstrated that Azelnidipine, a novel calcium channel blocker, ameliorates severity of colitis in DSS induced colitis in mice [23]. As well as this study is in agreement with the study of Rajinikanth B, which showed that Amlodipine possess a significant reduction in inflammation against acetic acid-induced ulcerative colitis in mice [24].

Regarding the anti-oxidant effect of Amlodipine, it decreased lipid peroxidation and increased the activity of SOD, but it didn't affect on GSH levels in this study. There was no statistical significance comparing with Indo control group. This is in agreement with several authors who described the antioxidant properties of calcium channel blockers (CCBs) as being due to either a direct scavenging effect or the preservation of the SOD activity. Under controlled experimental conditions; they may inhibit lipid peroxide formation at concentrations present in plasma. This antioxidant activity is found with high lipophilic CCBs when their chemical structure facilitates proton donating and resonance-stabilization mechanisms that quench the free radical reaction [25]. In addition the finding of this study isn't in harmony with the study of Arati S. Mahajan et al., which showed that Amlodipine improved the status of oxidative stress as shown by a decrease in MDA and increase in SOD levels in essentials hypertension patients. It, therefore, has antioxidative action in addition to the antihypertensive action [26]. Also the finding of this study isn't in agreement with the study of Morsy et al., which showed that Amlodipine exerts antioxidative effects in vitro and in vivo by inhibiting the oxidizability of the cell membrane and low-density lipoproteins. This effect was mediated by quenching free radicals due to its highly lipophilic properties and its chemical structure [9]. In addition, it isn't in agreement with the study of Pronobesh et al., which reported that Amlodipine acts as an antioxidant, regulates membrane fluidity and raises the activities of mitochondrial antioxidant enzymes [27].

\section{CONCLUSION}

In this study conclude that Amlodipine didn't produce obvious enhancement in enteropathy induced by Indomethacin.

\section{ACKNOWLEDGMENT}

The authors are thankful to Damascus University, faculty of pharmacy for providing funding and the necessary assistance. The authors are also thankful to AL-Assad university hospital for providing the assistance.

\section{FUNDING}

Nil

\section{AUTHORS CONTRIBUTIONS}

All the authors have contributed equally.

\section{CONFLICT OF INTERESTS}

The authors report no conflict of interest. The authors alone are responsible for the content and writing of this paper.

\section{REFERENCES}

1. Shin SJ, Noh C, Lim SG, Lee KM, Lee KJ. Non-steroidal antiinflammatory drug-induced enteropathy. Intest Res 2017;15:446-55.

2. Matsumoto T, Iida M, Nakamura S, Hizawa K, Kuroki F, Fujishima M. Preventive effect of immunosuppressive agents against indomethacin-induced small intestinal ulcers in rats. Dig Dis Sci 1994;39:787-95.

3. Lim YJ, Yang C. Non-steroidal anti-inflammatory drug-induced enteropathy. Clin Endosc 2012;45:138-44.

4. Graham DY, Opekun AR, Willingham FF, Qureshi WA. Visible small-intestinal mucosal injury in chronic NSAID users. Clin Gastroenterol Hepatol 2005;3565:55-9.

5. Takeuchi K. NSAID-induced small intestinal damage-roles of various pathogenic factors. Digestion 2015;91:218-32.

6. Park SC, Chun HJ, Kang CD, Sul D. Prevention and management of non-steroidal anti-inflammatory drug-induced small intestinal injury. World J Gastroenterol 2011;17:4647-53.

7. Tacheci I, Kopacova M, Rejchrt S, Bures J. Non-steroidal antiinflammatory drug-induced injury to the small intestine. Acta Medica (Hradec Kralove) 2010;53:3-11.

8. Mohammed NEM, Messiha BAS, Abo-Saif AA. Effect of amlodipine, lisinopril and allopurinol on acetaminopheninduced hepatotoxicity in rats. Saudi Pharm J 2016;24:635-44.

9. El Morsy EM, Kamel R, Ahmed MAE. Attenuating effects of coenzyme Q10 and amlodipine in ulcerative colitis model in rats. Immunopharmacol Immunotoxicol 2015;37:244-51.

10. Jagtap AG, Shirke SS, Phadke AS. Effect of polyherbal formulation on experimental models of inflammatory bowel diseases. J Ethnopharmacol 2004;90:195-204.

11. Nakhai LA, Mohammadirad A, Yasa N, Minaie B, Nikfar S, Ghazanfari G, et al. Benefits of zataria multiflora boiss in an experimental model of mouse inflammatory bowel disease. Evidence Based Complement Altern Med 2007;4:43-50.

12. Moron MS, Depierre JW, Mannervik B. Levels of glutathione, glutathione reductase and glutathione S-transferase activities in rat lung and liver. BBA-Gen Sub 1979;582:67-78.

13. Li X. Improved pyrogallol autoxidation method: a reliable and cheap superoxide-scavenging assay suitable for all antioxidants. J Agric Food Chem 2012;60:6418-24.

14. Patil NR, Rasal VP, Malabade RH. Screening of mandarin oil on indomethcin induced inflammatory bowel disease in wistar rats. Indian J Pharm Educ Res 2014;48:1-6.

15. Kheradmand A, Alirezaei M, Asadian P, Rafiei Alavi E, Joorabi S. Antioxidant enzyme activity and MDA level in the rat testis following chronic administration of ghrelin. Andrologia 2009;41:335-40. 
16. Reuter BK, Davies NM, Wallace JL. Nonsteroidal antiinflammatory drug enteropathy in rats: role of permeability, bacteria, and enterohepatic circulation. Gastroenterology 1997;112:109-17.

17. Drees DT, Robbins TL, Crago FL. Effect of low-residue foods on Indomethacin-induced intestinal lesions in rats. Toxicol Appl Pharmacol 1974;27:194-9.

18. Elson OC, Sartor BR, Tennyson SG, Riddl HR. Experimental models of inflammatory bowel diseases. Gastroenterology 1995;109:1344-67.

19. Nandi J, Saud B, Zinkievich JM, Yang ZJ, Levine RA. TNF-a modulates iNOS expression in an experimental rat model of an indomethacin-induced jejunoileitis. Mol Cell Biochem 2010;336:17-24

20. Yamada T, Deitch E, Specian DR, Perry AM, Sarto RrB, Grisham BM. Mechanisms of acute and crhonic intestinal inflammation induced by indomethacin. Inflammation 1993;17:641-62.

21. Kim YJ, Kim EH, Hahm KB. Oxidative stress in inflammationbased gastrointestinal tract diseases: challenges and opportunities. J Gastroenterol Hepatol 2012;27:1004-10.
22. Basivireddy I, Vasudevan A, Jacob $M$, Balasubramanian KA. Indomethacin-induced mitochondrial dysfunction and oxidative stress in villus enterocytes. Biochem Pharmacol 2002;64:339-49.

23. Kim K, Park J, Han Y, Lee SG, Shin SA. Azelnidipine, a novel calcium channel blocker, ameliorates severity of colitis in DSS induced colitis in DSS induced colitis in mice possibly by modulating tissue levels of TNF-alpha and IL-6. J Crohns Colitis 2017;11:29-30.

24. Rajinikanth B, Venkatachalam VV. Study on the effect of amlodipine on chemically induced inflammatory bowel disease using animal model. Int J PharmTech Res 2015;7:119-24.

25. Godfraind T. Antioxidant effects and the therapeutic mode of action of calcium channel blockers in hypertension and atherosclerosis. Philos Trans R Soc B Biol Sci 2005;360:2259-72.

26. Mahajan AS, Babbar R, Kansal N, Agarwal SK, Ray PC. Antihypertensive and antioxidant action of amlodipine and vitamin $C$ in patients of essential hypertension. J Clin Biochem Nutr 2007;40:141-7.

27. Pronobesh C. Protective role of the calcium channel blocker amlodipine against mitochondrial injury in ischemia and reperfusion injury of rat liver 2008;58:421-8. 